\title{
PERENCANAAN STRATEGIS SISTEM INFORMASI MENGGUNAKAN METODE WARD AND PEPPARD (STUDI KASUS: CV.GRAFIKA PRIMA MITRA AMBON)
}

\author{
Monice Frensca Johannis ${ }^{1)}$, Andeka Rocky Tanaamah ${ }^{2)}$, dan Hanna Prillysca Chernovita ${ }^{3)}$ \\ ${ }^{1,2,3}$ Sistem Informasi, Fakultas Teknologi Informasi, Universitas Kristen Satya Wacana \\ $1,2,3$ Jl. DR. O. Notohamidjojo No.1, Salatiga, 50711 \\ Email: 682015049@student.uksw.edu ${ }^{1)}$, atanaamah@uksw.edu ${ }^{2}$, hanna.chernovita@uksw.edu ${ }^{3)}$
}

\begin{abstract}
ABSTRAK
CV.Grafika Prima Mitra merupakan sebuah perusahaan yang bergerak dalam bidang percetakan pada CV.Grafika Prima Mitra belum menerapkan SI/TI sehingga kinerja menjadi tidak effisien karena belum mengunakan sistem sehingga perencanaan pengembangan belum terarah . Oleh karena itu, dilakukan penelitian tentang perencanaan strategis sistem informasi menggunakan kerangka ward and peppard. Dalam menyusun perencanaa strategis sistem informasi di CV.Grafika Prima Mitra dilakukan beberapa teknis analisis yakni: analisis lingkungan internal/eksternal menggunakan SWOT, sedangkan analisis lingkungan bisnis internal dan eksternal SI/TI menggunakan value chain. Pemetaan portofolio aplikasi SI di CV.Grafika Prima Mitra saat ini dan masa mendatang menggunkan Mc Farlan Strategic Gird. Berdasarkan hasil penelitian tersebut menghasilkan beberapa rekomendasi diantaranya pengembangan Web, Sistem Informasi Inventaris, Sistem Informasi Keuangan, Sistem Infromasi Pengelolaan persediaan barang dan bahan baku, serta Sistem Informasi Absensi dan cuti. Rekomendasi tersebut diharapkan dijadikan acuan pengembangan SI/TI perusahaan guna mencapai keunggulan kompetitif.
\end{abstract}

Kata kunci: Perencanaan Strategis SI/TI, Ward and Peppard Model, Mc farlan Strategic Gird, Value Chain, SWOT

\section{PENDAHULUAN}

Penerapan Teknologi Informasi (TI) dan Sistem Informasi (SI) saat ini sudah menjadi kebutuhan dan tuntutan di setiap organisasi, baik itu bagi organisasi maupun perusahaan. Teknologi Informasi dan Sistem Informasi (SI/TI) dapat lebih meningkatkan kinerja pada bidang usahanya, pengelolaan dan pengorganisasian sumber daya yang baik diharapkan dapat memberikan nilai tambah. Dan dengan hadirnya SI/TI pada perkantoran dan perusahaan, harus diimbangi juga dengan pengelolaan tata kelola SI/TI yang baik sehingga terwujudnya keselarasan antara Teknologi informasi dengan strategi bisnis perusahan tersebut.

CV.Grafika Prima Mitra merupakan sebuah perusahaan yang bergerak dalam bidang percetakan, berlokasi di Kota Ambon. CV.Grafika Prima Mitra didukung oleh tenaga kerja yang profesional dan alat-alat percetakan yang canggih berdasarkan hasil wawancara dengan dua orang karyawan CV.Grafika Prima Mitra belum menerapkan SI/TI atau aplikasi guna keperluan perusahaan dan pakar IT dalam perusahaan masih terbatas, aplikasi yang digunakan di setiap bagian pada perusahaan masih belum terintegrasi, tentunya memiliki dampak yang sangat besar dalam upaya pencapaian tujuan organisasi juga menimbulkan masalah dengan mencatat data di buku kemungkinan besar terjadi kebakaran maka bisnis akan berhenti dan menghambat jalannya pekerjaan sehingga membutuhkan perencanaan strategis guna mempermudah perusahaan. Agar bisa bertumbuh dan bersaing di era globalisasi yang semakin marak karena banyak saingan perusahaan percetakan di Kota Ambon.

Perencanaan Strategis Informasi pada CV.Grafika Prima Mitra adalah solusi yang terbaik guna mengembangkan usahanya yang didalamnya terdapat bagian keuangan dan administrasi, bagian produksi bagian pemasaran, bagian pracetak, bagian cetak dan bagian finising. Oleh karena itu CV.Grafika Prima Mitra memerlukan Perencanaan Strategis Sistem Informasi, yang mampu meningkatkan kinerja perusahaan agar berjalan dengan lebih efektif dan efisien. Metode yang digunakan dalam penelitian ini adalah metode Ward and Peppard karena metode ini dapat menghasilkan usulan usulan strategis yang mendukung perusahaan dan memiliki kerangka kerja yang jelas dan lebih cocok digunakan pada kondisi perusahaan saat ini Tools yang digunakan untuk mendukung metode ini adalah analisis SWOT untuk menghasilkan strategis usulan mengenai bisnis internal dan eksternal, Value chain untuk mengetahui kontribusi SI/TI pada fungsi bisnis perusahaan, strategis SI bisnis, McFarlan strategic grid untuk menentukan portofolio aplikasi sehingga perusahaan dapat meningkatkan kinerja.

Penelitian terdahulu dengan judul "Perencanaan Stategis Sistem Informasi dengan pendekatan Ward and Peppard (Studi Kasus: Klinik INTI Garut) yang bergerak dibidang pelayanan kesehatan bahwa penyusunan kerangka kerja perencanaan strategis sitem informasi menggunakan Ward and peppard sekaligus mengevaluasi penjabaran perencanaan strategis sitem 
informasi dan strategi bisnis menggunakan Balance Scorecard IT. Dan beberapa metode analisis seperti Value Chain Analisis, SWOT Analisis, PEST Analisis dam Five Force Model Analisis digunakan untuk menganalisis lingkungan bisnis internal dan eksternal. Strategic Grid McFarlen analisis digunakan untuk memetakan portofolio aplikasi. Penelitian ini menghasilkan sebuah rekomendasi untuk organisasi berupa prioritas pembangunan yang terbagi menjadi dua hal - hal terkait, pembentukan unit SI/TI dan pengembangan portolofio aplikasi yang mendukung keberlangsungan proses bisnis pada Klinik INTI Garut (Yosep Septiana 2017).

Penelitian lainnya yang melakukan penelitian di PD Alom Jaya mengunakan metode Ward and Peppard, tujuan dari penelitian ini adalah untuk meningkatkan daya saing perusahaan dengan meningkatkan keunggulan kompetitif perusahaan. Hasil Perencanaan Strategis Sistem Informasi ini nantinya akan membantu perusahaan dalam beberapa aspek seperti penjualan dan pemasaran produk perusahaan, serta bidang administrasi perusahaan guna memberikan layanan terbaik bagi pelanggan PD Alom Jaya. Teknik analisis yang digunakan seperti SWOT, Value Chain analysis, Porter, dan CSF (Critical Succes Factor) (Elisabeth, Erly Farieda 2014).

Penelitian yang terkait tentang Perencanaan Strategis Sistem Informasi sebelumnya pernah dilakukan dengan judul "Perencanaan Strategis Sistem Informasi dalam Meningkatkan Keunggulan Kompetitif Menggunakan Metode Ward and Peppard (Studi Kasus SMK Diponegoro Salatiga) ". Penelitian ini membahas tentang menyelaraskan strategis visi dan misi yang dimiliki SMK Diponegoro dengan strategi SI/TI dalam mewujudkan keunggulan kompetitif pada organisasi. Dari penelitian tersebut didapatkan hasil berupa Perumusan strategis SI/TI dan Manajemen Informasi untuk memajukan pelayanan sekolah, serta menghasilkan solusi SI/TI dalam mendukung aktivitas utama sekolah (Thomas, Krista 2015).

Penelitiannya tentang strategis sistem informasi dan Teknolosi informasi dengan judul "Perencanaan Strategis Sistem Informasi pada perusahaan Perkebunan Kelapa Sawit Pengumpulan Menengah di Kalimantan Barat dengan Menggunakan Metode Ward and Peppard" penelitian tersebut bertujuan untuk menghasilkan suatu perencanaan strategis sistem informasi yang tepat sesuai dengan kebutuhan perusahaan. Perencanaan strategis ini menghasilkan portofolio aplikasi yang bersifat High potential seperti SCM (Supply Chain Management), ECommerce, CRM (Costomer Relationship Management) guna memudahkan perusahaan dalam pemasokan bahan baku yang stabil dari petani, dan memudahkan dalam penjualan produk perusahaan, serta menjaga hubungan kerja pelayanan yang baik dengan pelanggan. Penelitian ini juga menggunakan teknik analis seperti SWOT, Value Chain, Analisis 5 modal daya saing Porter, Five force Analisys (M.Qadafi Khairuzzaman 2015).

\section{RUANG LINGKUP}

Dalam penelitian ini permasalahan mencakup:

1. Cakupan permasalahan dalam penelitian ini adalah: Pada CV.Grafika Prima Mitra perusahaan yang bergerak dalam bidang percetakan, belum menerapkan SI/TI atau aplikasi guna keperluan perusahaan dan pakar IT dalam perusahaan masih terbatas, aplikasi yang digunakan di setiap bagian pada perusahaan masih belum terintegrasi Untuk itu Perencanaan Strategis Informasi pada CV.Grafika Prima Mitra adalah solusi yang terbaik guna mengembangkan usahanya

2. Batasan penelitian ini hanya mengacu pada penerapan rencana strategis Sistem Informasi

3. Rencana hasil yang didapatkan penelitian ini hanya mengacu pada penerapan rencana strategis Sistem Informasi

\section{BAHAN DAN METODE}

Perencanaan strategis SI/TI merupakan proses identifikasi dokumen ISSP aplikasi SI berbasis komputer yang akan mendukung organisasi dalam pelaksanaan rencana bisnis dan merealisasikan tujuan bisnisnya. Perencanaan strategis SI/TI terhadap kinerja bisnis dan kontribusi bagi organisasi dalam memilih langkah langkah strategis. Selain itu, perencanaan strategis SI/TI juga menjelaskan berbagai tools, teknik, dan kerangka kerja bagi manajemen untuk menyelaraskan strategi SI/TI dengan strategi bisnis, bahkan mencari kesempatan baru melalui penerapan teknologi yang inovatif (Muhammad Afrianto, Eko Darwiyanto, \& Gede Agung Ary Wisudiawan 2016).

Pendekatan metodologi versi Ward and Peppard ini dimulai dari analisis kondisi bisnis dan investasi SI/TI yang sudah berjalan yang dinilai kurang efektif, lalu menganalisa kondisi bisnis eksternal sehingga dapat meningkatkan keunggulan kompetitif suatu organisasi. Analisis pemanfaatan SI/TI apakah sudah maksimal, lalu membandingkannya dengan kecenderungan kondisi SI/TI yang digunakan di luar. Karena, terkadang kurang bermanfaatnya SI/TI bagi organisasi disebabkan SI/TI lebih fokus ke teknologi, bukan berdasarkan kebutuhan bisnis. Berikut ini tahapan metodologi versi Ward and Peppard. Tahapan masukan terdiri dari:

1. Analisis lingkungan bisnis internal, yang mencakup aspek-aspek strategi bisnis saat ini, sasaran, sumber daya, proses, serta budaya nilai-nilai bisnis organisasi.

2. Analisis lingkungan bisnis eksternal, yang mencakup aspek-aspek ekonomi, industri, dan iklim bersaing perusahaan.

3. Analisis lingkungan SI/TI internal, yang mencakup kondisi SI/TI organisasi dari perspektif bisnis saat ini, bagaimana kematangannya (maturity), bagaimana kontribusi terhadap bisnis, keterampilan sumber daya manusia, sumber daya dan infrastruktur teknologi, termasuk juga bagaimana portofolio dari SI/TI yang ada saat ini. 
4. Analisis lingkungan SI/TI eksternal, yang mencakup tren teknologi dan peluang pemanfaatannya, serta penggunaan SI/TI oleh kompetitor, pelanggan dan pemasok.

Sedangkan tahapan keluaran merupakan bagian yang dilakukan untuk menghasilkan suatu dokumen perencanaan strategis SI/TI yang terdiri dari:

1. Strategi SI bisnis, yang mencakup bagaimana setiap unit atau fungsi bisnis akan memanfaatkan SI/TI untuk mencapai sasaran bisnisnya, portofolio aplikasi dan gambaran arsitektur informasi.

2. Strategi TI, yang mencakup kebijakan dan strategi bagi pengelolaan teknologi dan sumber daya manusia $\mathrm{SI} / \mathrm{TI}$.

3. Strategi Manajemen SI/TI, yang mencakup elemenelemen umum yang diterapkan melalui organisasi, untuk memastikan konsistensi penerapan kebijakan SI/TI yang dibutuhkan. (Satwika Parama Putra, Kemas Harmat SW, \& Eda Guslinar Perdana 2014).

\subsection{Tahapan Penelitian}

Penelitian yang digunakan dalam penelitian CV.Grafika Prima Mitra Kota Ambon menggunakan metode kualitatif yaitu pengamatan, wawancara, atau penelaahan dokumen. Metode kualitatif ini digunakan karena beberapa pertimbangan. Pertama, menyesuaikan metode kualitatif lebih mengenal dan merasakan apa yang dibutuhkan perusahaan Kedua, metode kualitatif menyajikan secara langsung hakikat hubungan antara peneliti dan responden bisa menjelaskan kondisi yang sebenarnya sehingga data bersifat primer langsung didapat di tempat yang diteliti (Lexi Moleong 2013).

Adapun tahadapan penelitian yang dilakukan ditampilkan pada gambar 1

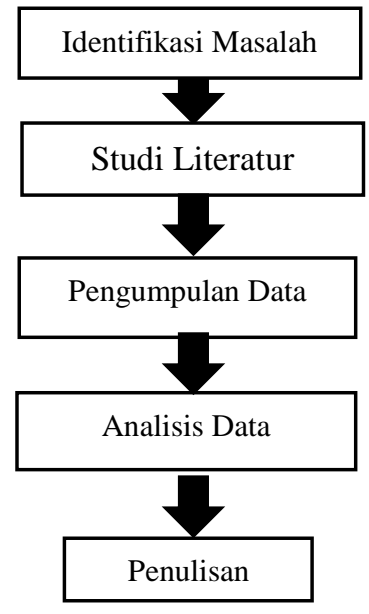

Gambar 1. Tahapan Penelitian
Keterangan Gambar 1 :

1. Identifikasi Masalah

Tahap awal penelitian adalah mengidentifikasi masalah yang dihadapi CV.Grafika Prima Mitra Kota Ambon, untuk mengetahui masalah maka penulis melakukan wawancara kepada responden yaitu karyawan dan menemukan masalah bahwa pada CV.Grafika Prima Mitra Kota Ambon belum mengunakan sistem sehingga perencanaan pengembangan belum terarah.

2. Studi Literatur

Tahap selanjutnya studi literatur yang dilakukan dengan mencari penelitian atau artikel ilmiah yang topiknya terkait dengan penelitian sekarang, sehingga dapat lebih memperkuat dan mengembangkan topik yang akan dibahas oleh peneliti pada penelitian ini tentang perencanaan strategis sistem informasi yang serupa dengan peneliti atau artikel ilmiah lain.

3. Pengumpulan Data

Tahap selanjutnya adalah melakukan pengumpulan data dengan cara observasi dan wawancara kepada karyawan CV.Grafika Prima Mitra Kota Ambon.

4. Analisis Data

Tahap selanjutnya melakukan analisis data yang telah dikumpulkan peneliti melalui wawancara dan data tersebut nantinya dijadikan sebagai acuan proses penyusunan perencanaan strategis sistem informasi

5. Penulisan

Tahap selanjutnya adalah tahap penulisan renstra berdasarkan data yang dikumpulkan sehingga untuk membuat usulan - usulan strategis pada perusahaan.

\subsection{Analisis Menggunakan Metode Ward and Peppard}

Melakukan analisis lingkungan internal dan eksternal bisnis dan SI dengan menggunakan beberapa macam analisis, antara lain:

1. Analisis Lingkungan Internal Bisnis : pada tahap ini, melakukan analisis terhadap semua yang berhubungan dengan kegiatan bisnis internal CV.Grafika Prima Mitra kota Ambon dan Analisis internal adalah analisis yang dilakukan terhadap kekuatan serta kelemahan sebuah perusahaan, kekuatan berarti dimana sebuah perusahaan dapat memanfaatkan serta memenuhi target pasar, dan kelemahan adalah dimana perusahaan mengalami keterbatasan.

2. Analisis Lingkungan Eksternal SI/TI organisasi : pada tahap ini, menganalisis SI/TI apa saja yang sudah di implementasi pada CV.Grafika Prima Mitra kota Ambon. Kemudian faktor eksternal yang akan mempengaruhi proses pada bisnis CV.Grafika Prima Mitra kota Ambon. Metode yang digunakan ialah SWOT (Strengths, Weaknesses, Opportunities, Threats) Analisis Value chain berguna untuk mengetahui perkembangan teknologi di luar perusahaan dan menelaah teknologi tersebut guna dimanfaatkan dalam mendukung perencanaan 
strategis bisnis CV.Grafika Prima Mitra Kota Ambon di masa yang akan datang.

3. Menentukan Strategi SI/TI menggunakan Mc Farlan Strategic Grid : Mc Farlan strategic grid digunakan untuk memetakan aplikasi SI berdasarkan kontribusinya terhadap organisasi atau perusahaan CV.Grafika Prima Mitra Kota Ambon. Pemetaan dilakukan pada empat kuadran (strategic, high potential, key operation, and support).

4. Penyusunan usulan pada pengembangan aplikasi yang disesuaikan dengan portofolio aplikasi Mc Farlan Strategic Grid. Hasil analisi akan digunakan untuk penyusunan strategi dibuat dan disesuaikan dengan kebutuhan SI/TI sehingga menghasilkan Rancangan Strategis SI/TI untuk CV.Grafika Prima Mitra.

\section{PEMBAHASAN}

Berikut penyusunan perencanaan strategis strategis sistem informasi pada CV.Grafika Prima Mitra Ambon menggunakan metode Ward and Peppard,

\subsection{Analisis Lingkungan Internal/Eksternal Bisnis}

Analisis Internal dan Eksternal bisnis Menggunakan Analisis SWOT (Strengths, Weaknesses, Opportunities, Threats) digunakan untuk menilai kekuatan dan kelemahan pada sumber daya yang dimiliki CV.Grafika Prima Mitra. Kemudian melakukan identifikasi kekuatan yang berfungsi untuk mengetahui kekuatan yang dimiliki dan mempertahankan bahkan meningkatkan sebagai modal bersaing, identifikasi kelemahan berfungsi agar mengetahui apa saja kelemahan yang ada sehingga CV.Grafika Prima Mitra bisa merubah kelemahan dengan mencari solusi untuk menutupi kelemahan tersebut guna kesejahteraan perusahaan. Dengan mengetahui peluang saat ini atau peluang di masa yang akan datang CV.Grafika Prima Mitra mampu mencapai peluang, mempersiapkan diri dan menyiapakan strategis lebih awal dan terencana dengan sangat baik agar peluang yang sudah diidentifikasi dapat direalisasikan. Selain itu dalam mewujudkan peluang dan kesempatan mempertahankan kelangsungan bisnis organisasi tentu akan mengalami ancaman - ancaman yang perlu diidentifikasi jalan keluarnya sehingga perusahan dapat meminimalkan ancaman tersebut. Berikut gambaran analisa SWOT dan perancangan strategis. Pada table 1

Table 1. Hasil Analisis SWOT

\begin{tabular}{|c|c|c|}
\hline & Kekuatan (S) & Kelemahan (W) \\
\hline Ynternal & \begin{tabular}{|ll} 
1. & Memiliki SOP yang sudah jelas \\
2. & Mesin percetakan sudah memadai \\
3. & Tenaga kerja professional \\
4. & Harga jual murah \\
5. & Tempat strategi di pusat kota \\
& Ambon \\
6. & Memiliki langganan tetap (semua \\
& jemaat gereja di kota Ambon)
\end{tabular} & $\begin{array}{l}\text { 1. Mesin sablon belum ada } \\
\text { 2. Infrastruktur IT tidak memadai } \\
\text { 3. Belum menggunakan sistem informasi }\end{array}$ \\
\hline Peluang (O) & Strategis (S-O) & Strategis $(\mathrm{W}-\mathrm{O})$ \\
\hline $\begin{array}{l}\text { 1. Pasar Marketing yang } \\
\text { luas } \\
\text { 2. Terbukanya peluang } \\
\text { ekspor } \\
\text { 3. Maraknya pemakaian } \\
\text { rutin di gereja } \\
\text { 4. Membuka cabang baru }\end{array}$ & $\begin{array}{l}\text { 1. Mesin percetakan yang sudah } \\
\text { memadai sehingga pesanan luar } \\
\text { daerah bisa dilakukan } \\
\text { 2. Harga jual murah sehingga } \\
\text { memiliki pelanggan tetap dan pasar } \\
\text { Marketing semakin luas } \\
\text { 3. Membuka cabang baru yang } \\
\text { tempatnya dekat dengan } \\
\text { Mahasiswa }\end{array}$ & $\begin{array}{l}\text { 1. Melakukan pengadaan mesin sablon } \\
\text { 2. Membangun Sistem Informasi untuk } \\
\text { kebutuhan perusahaan } \\
\text { 3. Melakukan perekrutan pegawai baru } \\
\text { yang punya pendidikan dan keahlian } \\
\text { dalam bidang IT }\end{array}$ \\
\hline
\end{tabular}




\begin{tabular}{|l|l|l|}
\hline \multicolumn{1}{|c|}{ Ancaman (T) } & \multicolumn{1}{|c|}{ Strategis (S-T) } & \multicolumn{1}{c|}{ Strategis (W-T) } \\
\hline $\begin{array}{l}\text { 1. Bersaing dengan } \\
\text { perusahaan percetakan }\end{array}$ & 1. Meningkatkan pelayanan kualitas & 1. Meningkatkan promosi dan \\
yang lain & peningkatan kompetensi SDM SI \\
$\begin{array}{l}\text { 2. Muncul teknologi baru } \\
\text { Malam bidang penjualan }\end{array}$ & $\begin{array}{l}\text { Melakukan promosi penjualan } \\
\text { dalam bentuk online }\end{array}$ & $\begin{array}{l}\text { Memberikan pelatihan pada karyawan } \\
\text { baru khususmya pada bidang IT }\end{array}$ \\
\hline
\end{tabular}

Berdasarkan hasil analisis SWOT table 1 pada CV.Grafika Prima Mitra terdapat Kekuatan (S): memiliki SOP yang sudah jelas, mesin percetakan sudah memadai, tenaga kerja professional, harga jual murah, tempat strategi di pusat kota ambon, memiliki langganan tetap (semua jemaat gereja di kota ambon). Kelemahan (W): mesin sablon belum ada, infrastruktur IT tidak memadai, belum menggunakan sistem informasi. Peluang (O): pasar marketing yang luas, terbukanya peluang ekspor, maraknya pemakaian rutin di gereja, mambuka cabang baru. Ancaman (T): bersaing dengan perusahaan percetakan yang lain, muncul teknologi baru dalam bidang penjualan. Maka dapat dirumuskan rumusan guna untuk Perencanaan Strategis Sistem Informasi

1. Mengembangkan kekuatan dengan mengoptimalkan peluang (S-O)

Mesin percetakan yang sudah memadai sehingga pesanan luar daerah bisa dilakukan, Mesin percetakan yang sudah memadai sehingga pesanan luar daerah bisa dilakukan, Membuka cabang baru yang tempatnya dekat dengan Mahasiswa.

2. Mengembangkan kekuatan untuk mengatasi ancaman (S-T)

Meningkatkan pelayanan kualitas yang prima, Melakukan promosi penjualan dalam bentuk online

3. Meminimalkan kelemahan untuk memanfaatkan peluang $(\mathrm{W}-\mathrm{O})$

Melakukan pengadaan mesin sablon, Membangun Sistem Informasi untuk kebutuhan perusahaan, Melakukan perekrutan pegawai baru yang punya pendidikan dan keahlian dalam bidang IT.

4. Meminimalkan kelemahan dan menghindari ancaman (W-T)

Meningkatkan promosi dan peningkatan kompetensi SDM SI, Memberikan pelatihan pada karyawan baru khususmya pada bidang IT

\subsection{Analisis Lingkungan Internal SI/TI dan Eksternal SI/TI}

Proses bisnis akan didefinisikan dalam aktivitas-aktivitas yang ada pada sebuah perusahaan atau organisasi yang mempunyai nilai-nilai untuk tercapainya tujuan perusahaan. Pemetaan lingkungan Internal dan Eksteral SI/TI menggunakan Porter's Value Chain. Didalamnya proses bisnis dibagi menjadi dua aktivitas yaitu aktivitas utama dan pendukung antara lain sebagai berikut pada gambar 3

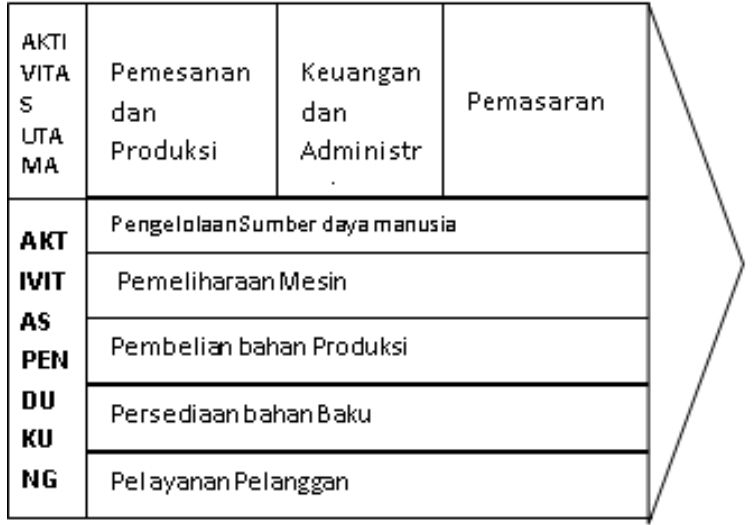

Gambar 3. Hasil Analisis Value Chain

Gambar 3 merupakan hasil analisis value chain, yaitu:

1. Aktivitas Utama (Main activity) terdiri dari :

Pemesanan dan Produksi suatu bagian yang bertugas mengatur pesanan dan kegiatan-kegiatan yang diperlukan bagi terselenggaranya proses produksi.

Keuangan dan Administrasi suatu bagian yang bertugas menyusun anggaran belanja, perencanaan keuangan, serta membuat pembukuan tentang semua yang berkaitan dengan proses pembiayaan dan pengeluaran keuangan agar penggunaan biaya dapat efektif dan efisien.

Pemasaran suatu bagian yang merupakan aktivitas utama atau pokok dalam menyusun perencanaan analisis peluang pasar perusahaan untuk mempertahankan kelangsungan perusahaan dan memperoleh laba, proses pemasaran, promosi, dimulai jauh sebelum beberapa barang diproduksi.

2. Aktivitas pendukung (Support Activity) terdiri dari : Pengelolaan sumber daya manusia suatu bagian yang mengatur karyawan, penghargaan dan tingkat kepatuhan karyawan, mengembangkan potensial karyawan dan organisai.

Pemeliharaan Mesin suatu bagian yang bertugas menjaga, memelihara, perbaikan mesin bila ada yang rusak agar proses percetakan tidak berhenti.

Pembelian bahan Produksi suatu bagian yang bertugas memahami, menganalisa, menyediakan bahan produksi guna memenuhi kebutuhan perusahaan agar proses percetakan tidak berhenti.

Persediaan bahan Baku suatu bagian yang bertugas mengecek sisa gudang guna melancarkan produksi agar tidak ada keterlambatan dalam pembelian bahan produksi dan proses percetakan. 
Pelayanan Pelanggan suatu bagian yang bertugas melayani pelanggan saat melakukan pemesanan dan pengambilan barang.

Aktivitas Utama dan Aktivitas Pendukung pada CV.Grafika Prima Mitra, telah di sebutkan di bagian atas, maka dilanjutkan dengan analisis antara stakeholder dengan aktivitas utama dan pendukung pada table 2 .

Tabel 2. Hubungan Stakeholder dengan Aktivitas Organisasi

\begin{tabular}{|c|c|c|}
\hline Aktivitas & $\begin{array}{l}\text { CV.Grafika Prima } \\
\text { Mitra }\end{array}$ & Pelanggan \\
\hline $\begin{array}{ll}\text { Aktivitas Utama } \\
\text { 1. } & \text { Pemesanan dan } \\
\text { Produksi } \\
\text { 2. } \\
\text { Keuangan dan } \\
\text { Administrasi } \\
\text { 3. Pemasaran }\end{array}$ & $\begin{array}{l}\text { Direktur, } \\
\text { Manager, Sales } \\
\text { manager, } \\
\text { Administrasi }\end{array}$ & $\begin{array}{l}\text { Customer / } \\
\text { Nasabah }\end{array}$ \\
\hline 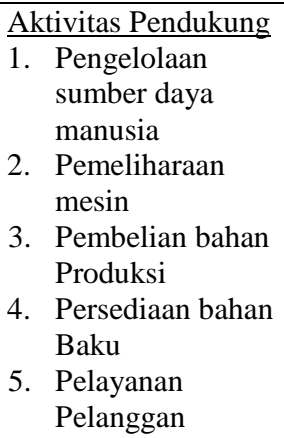 & $\begin{array}{l}\text { Direktur, } \\
\text { Manager, Sales } \\
\text { manager, Staff, } \\
\text { seluruh karyawan, } \\
\text { Administrasi }\end{array}$ & $\begin{array}{l}\text { Customer / } \\
\text { Nasabah }\end{array}$ \\
\hline
\end{tabular}

\subsection{Arsitektur Sistem Informasi}

Tahapan Arsitektur Sistem Informasi menjelaskan pendefinisian sistem informasi pada CV.Grafika Prima Mitra, yaitu: CV memiliki beberapa jenis aplikasi yang digunakan dalam aktivitas fungsi yang dilakukan. Beberapa aplikasi yang sudah digunakan dapat dilihat pada Tabel 3

Tabel 3. Arsitektur Aplikasi

\begin{tabular}{|l|l|l|l|}
\hline No & $\begin{array}{l}\text { Nama } \\
\text { Aplikasi }\end{array}$ & Pengguna Aplikasi/SI & Status \\
\hline 1 & $\begin{array}{l}\text { Microsoft } \\
\text { Office }\end{array}$ & $\begin{array}{l}\text { 1. Pemilik } \\
\text { perusahaan } \\
\text { 2agian Pemesanan } \\
\text { dan Produksi } \\
\text { Bagian Keuangan } \\
\text { dan Administrasi } \\
\text { Bagian Pemasaran }\end{array}$ & Upgrade \\
\hline 2 & WhatsApp & $\begin{array}{l}\text { 1. Pemilik perushaan } \\
\text { 2. Seluruh karyawan }\end{array}$ & Upgrade \\
\hline
\end{tabular}

Berdasarkan tabel 3 Arsitektur Aplikasi yang digunakan pada CV.Grafika Prima Mitra terdiri dari Microsoft
Office dengan pengguna aplikasi pemilik perusahaan, bagian pemesanan dan produksi, bagian keuangan dan administrasi, bagian pemasaran. Untuk aplikasi WhatsApp (handphone) dengan pengguna aplikasi, pemilik perusahaan dan seluruh karyawan. Kedua aplikasi ini dengan status Upgrade atau pergantian dari versi lama ke versi lebih baru atau lebih baik

\subsection{Arsitektur Teknologi}

Pemanfaatan teknologi di CV.Grafika Prima Mitra bisa dilihat pada Tabel 4

Tabel 4. Arsitektur Aplikasi

\begin{tabular}{|c|c|c|}
\hline Kelompok & Jenis & Jumlah \\
\hline Hardware : & \multirow[b]{2}{*}{ HP } & \\
\hline 1. $\mathrm{PC}$ & & 4 \\
\hline 2. Input Devices & Scanner, Mouse & 1,4 \\
\hline 3. Output Devices & Printer & 4 \\
\hline 4. Storage & Flashdisk & 2 \\
\hline 5. Network & Wifi, LAN & 1,3 \\
\hline 6. Telepon & Telepon & 1 \\
\hline Software: & \multirow[b]{2}{*}{$\begin{array}{l}\text { Windows } 2007, \\
2010\end{array}$} & \multirow[b]{2}{*}{2,2} \\
\hline 1. Sistem Operasi & & \\
\hline 2. Word Processing & $\begin{array}{l}\text { Ms Word 2010, } \\
2013\end{array}$ & 3,1 \\
\hline 3. Spread Sheet & $\begin{array}{ccc}\text { Ms } & \text { Excel } 2010, \\
2016 & & \end{array}$ & 3,1 \\
\hline 4. Desain Grafis & $\begin{array}{l}\text { Photoshop, Corel } \\
\text { Draw }\end{array}$ & 1,1 \\
\hline 5. Security & Smadav, Apk & 2,2 \\
\hline
\end{tabular}

Berdasarkan hasil Tabel 4 Arsitektur Aplikasi pada kelompok Hardware terdapat PC jenis HP jumlah 4 unit, Input Devices jenis Scanner jumlah 1 unit, Input Devices jenis Mouse jumlah 4 unit, Output Devices jenis Printer jumlah 4 unit, Storage jenis Flashdisk jumlah 2 unit, Network jenis Wifi jumlah 1 router, Netrowk jenis LAN jumlah 1 rol, Telepon jenis telepon jumlah 1 unit. Kemudian pada kelompok Software terdapat Sistem Operasi jenis Windows 2007 jumlah 2, Windows 2010 jumlah 2, Word Processing jenis Microsoft Word 2010 jumlah 3, Microsoft Word 2016 jumlah 1, Desain Grafis jenis Photoshop jumlah 1, Corel Draw jumlah 1, Security jenis Smadav jumlah 2, Apk jumlah 3.

\subsection{Portofolio Aplikasi}

Hasil dari penjabaran strategis SI/TI dan Strategis bisnis, membentuk portofolio dengan prioritas dan blueprint strategis SI/TI yang berpedoman pada $M c$ Farlan Strategic Grid. Metode tersebut digunakan untuk memetakan aplikasi SI berdasarkan konstribusinya terhadap organisasi. Pemetaan ini dilakukan pada empat kaudran (Strategic, High Potential, Key Operation, and Support). Dari hasil analisi menghasilkan gambar kontribusi sebuah aplikasi SI terhadap organisasi dan pengembangan di masa yang akan datang. Pada table 5 
Tabel 5. Strategic Grid Mc Farlan

\begin{tabular}{|l|l|}
\hline Strategic & High Potential \\
\hline $\begin{array}{l}\text { 1. Sistem Informasi } \\
\text { Inventaris }\end{array}$ & $\begin{array}{l}\text { Sistem Informasi } \\
\text { Absensi dan Cuti }\end{array}$ \\
\hline Key Operational & Support \\
\hline 2. Sistem Informasi & 5. Website \\
Keuangan Informasi & \\
3. Sistem pengelolaan persediaan \\
parang dan bahan baku
\end{tabular}

Berdasarkan hasil tabel 5 strategic grid mc farlan terdapat 4 kaudran sebagai berikut :

1. Kuadran Support

Kuadran Support ini merupakan kuadran dimana setiap sistem informasi yang ada adalah aplikasiaplikasi yang mendukung terhadap aktivitas proses bisnis di CV.Grafika Prima Mitra. Namun keberadaan sistem informasi ini tidak memberikan pengaruh yang besar apabila terdapat kerusakan atau kegagalan pada sistem informasi. Website pada CV.Grafika Prima Mitra dibutuhkan untuk sarana promosi dan layanan kepada calon pembeli. Dengan adanya aplikasi ini dapat meningkatkan kredibilitas sebagai wadah untuk mencari informasi yang ada pada perusahaan sehingga memudahkan pelanggan untuk mendapat sumber informasi terkait dengan produk maupun hal lainya secara rinci dan lengkap.

2. Kuadran Key Operational

Kuadran Key Operational ini merupakan posisi dimana sistem informasi sangat memberikan kemudahan bagi operasional CV.Grafika Prima Mitra. Pada tahap ini sudah disadari bahwa kelangsungan bisnis cukup dipengaruhi oleh keberadaan teknologi informasi, namun kuadran ini masih belum menunjukkan bahwa teknologi informasi berperan utama dalam mempengaruhi kelangsungan bisnis.

1) Sistem informasi keuangan sangat dibutuhkan untuk mengelola laporan keuangan agar lebih baik dan cepat. Sistem informasi keuangan ini kiranya dapat mengurangi resiko dari kesalahan perhitungan sehingga laporan keuangan menjadi lebih akurat. Manajemen juga akan lebih dimudahkan dengan adanya sistem informasi untuk dapat menjaga asset yang dimiliki perusahaan karena bisa mencatat semua informasi yang ada di perusahaan.

2) Sistem informasi pengelolaan persediaan barang sangat dibutuhkan untuk memudahkan proses mencatat setiap jenis persedian barang yang disimpan di gudang, dan mengurangi terjadinya kesalahan pengguna selama proses penginputan data dan memudahkan manajemen perusahaan dalam pengawasan guna mengurangi resiko kehilangan barang.

3) SAP berfungsi untuk pengelolahan customer untuk melakukan order, juga membantu dalam proses kontrol kualitas.

3. Kuadran High Potential

Kuadran High Potential ini merupakan kuadran dimana sistem informasi bukan hanya dianggap penting bagi kelangsungan dan proses bisnis internal, tetapi juga proses bisnis yang terjadi pada transaksi atau aktivitas bisnis eksternal operasional perusahaan. Pada kuadran ini juga, kebutuhan terhadap sistem informasi atau teknologi informasi dianggap sebagai keunggulan kompetitif bagi perusahaan, dengan kata lain kuadran ini berpotensi terhadap kesuksesan pada kelangsungan bisnis. Sistem Infromasi absensi dan cuti merupakan sistem informasi yang dibuat untuk sarana absensi pegawai, agar pencatatan tidak menggunakan kertas, semua data absensi dan cuti tersimpan rapi dan aman di server.

4. Kuadran Strategic

Kuadran Strategic ini merupakan kuadran dimana setiap sistem informasi dianggap berpengaruh terhadap kelangsungan bisnis dimasa yang akan datang. Bahkan kuadran ini memungkinkan operasional CV.Grafika Prima Mitra untuk mempertimbangkan dalam mempertahankan kesuksesan dalam menjalankan bisnis. Sistem informasi ini sangat dibutuhkan di perusahaan untuk memudahkan pihak terkait pada CV.Grafika Prima Mitra dalam mendata inventaris perusahaan ke dalam sistem tersebut, inventaris yang dimaksud seperti: komputer, mesin cetak, mesin kalator, mesin fotocopy, mesin cutting, mesin laminating dan perlengkapan peralatan perusahaan.

\subsection{Rencana Implementasi}

Rencana implementasi pada CV.Grafika Prima Mitra dilakukan secara bertahap, dalam kurun waktu 5 tahun. Hal ini bertujuan untuk membantu perusahaan memperhitungkan pembiayaan SI pada perusahaan guna kemajuan SI/TI perusahaan. Berikut adalah susunan tahapan rencana implementasi pada CV.Grafika Prima Mitra pada Tabel 6. 
Tabel 6. Rencana mplementasi SI pada CV.Grafika Prima Mitra

\begin{tabular}{|l|l|l|l|l|l|l|}
\hline \multirow{2}{*}{ Rekomendasi } & \multicolumn{5}{|c|}{ Tahun } & ket \\
\hline & 2019 & 2020 & 2021 & 2022 & 2023 & \\
\hline $\begin{array}{l}\text { Sistem Informasi } \\
\text { Inventaris }\end{array}$ & & & & & & \\
\hline $\begin{array}{l}\text { Sistem Informasi } \\
\text { Keuangan }\end{array}$ & & & & & & Baru \\
\hline $\begin{array}{l}\text { Sistem Informasi } \\
\text { pengelolaan } \\
\text { persediaan } \\
\text { barang dan bahan } \\
\text { baku }\end{array}$ & & & & & & Baru \\
\hline SAP & & & & & V & \\
\hline $\begin{array}{l}\text { Sistem Informasi } \\
\text { Absensi dan } \\
\text { Cuti }\end{array}$ & & & & & Baru \\
\hline Website & & V & & & Baru \\
\hline
\end{tabular}

Berdasarkan table 6 Rencana Implementasi SI CV. Grafika Prima Mitra terdapat 5 Rekomendasi baru 1 Upgrade secara bertahap yaitu Sistem Informasi Inventaris yang akan dilakukan pada tahun 2020 (baru), Sistem Informasi Keuangan yang akan dilakukan pada tahun 2021 (baru), Sistem Informasi pengelolaan persediaan barang dan bahan baku yang akan dilakukan pada tahun 2022 (baru), SAP yang akan dilakukan pada tahun 2023 (baru), Sistem Informasi Absensi dan Cuti yang akan dilakukan pada tahun 2023 (baru), dan yang terakhir Website yang akan dilakukan upgrade pada tahun 2020.

\section{KESIMPULAN}

Hasil analisis yang telah dilakukan, menghasilkan sistem informasi pada CV.Grafika Prima Mitra ternyata belum menerapkan SI/TI sehingga kinerja menjadi tidak effisien karena belum mengunakan sistem sehingga perencanaan pengembangan belum terarah. Sehingga dengan adanya perencanaan Strategis menggunakan metode Ward and Peppard dapat diketahui kekuatan, kelemahan, peluang serta ancaman yang dimiliki CV.Grafika Prima Mitra. Selain itu juga dapat mengetahui aktivitas utama dan pendukung yang dijelaskan dengan menggunakan value chain. Hasil analisis lingkungan Sistem informasi internal dan eksternal menunjukan bahwa Sistem informasi belum berjalan dengan baik, sehingga CV.Grafika Prima Mitra membutuhkan pengembangan sistem informasi sehingga setiap akivitasnya dapat berjalan dengan optimal.

Oleh karena itu pengembangan strategis sistem informasi yang telah dijabarkan pada portofolio McFarlan Grid yang menghasilkan beberapa rekomendasi diantaranya pengambangan Web, Sistem Informasi Inventaris, Sistem Informasi Keuangan, Sistem Informasi pengelolaan persediaan barang dan bahan baku, SAP, serta Sistem Informasi Absensi dan Cuti.

\section{SARAN}

Saran untuk penelitian selanjutnya adalah memberikan dan menerapkan perencanaan strategis SI yang tepat melalui tahapan penyusunan perencanaan strategis sistem informasi. Penelitian ini berfokus pada sistem informasi, maka di masa depan perlu mengkaji dari teknologi informasi, yaitu hardware, jaringan dan integrasi sistem. Selain itu, diperlukan strategi untuk meningkatkan kapasitas SDM SI agar mendukung proses bisnis perusahaan juga membuat kemudahan pada pekerjaan.

\section{DAFTAR PUSTAKA}

Yosep Septiana, 2017, Perencanaan Strategis Dengan Pendekatan Ward and Peppard Model (Studi Kasus: Klinik INTI Garut), Jurnal Wawasan Ilmiah, vol 8

Farieda, Perencanaan Strategis Sistem Informasi PD. Alom Jaya (AJ). Universitas Gunadarma. 2011.

Thomas, Krista, 2014, Perencanaan Strategis Sistem Informasi dalam Meningkatkan Keunggulan Kompetitif Menggunakan Metode Ward \& Peppard (Studi Kasus SMK Diponegoro Salatiga, Program Studi Sistem Informasi FTI-UKSW.

M.Qadafi Khairuzzaman, 2015, Perencanaan Strategis Sistem Informasi pada Perusahaan Perkebunan Kelapa Sawit Pengumpul Menengah di Kalimantan Barat dengan Menggunakan Metode Ward and Peppard, VOL.3 NO.1, Jurnal Khatulistiwa Informatika (https://ejournal.bsi.ac.id/ejurnal/index.php/khatulis tiwa/article/view/1655/1207

Muhammad Afriano, Eko Darwiyanto, \& Gede Agung Ary Wisudiawan, 2016, Perencanaan Strategis Sistem Informasi Menggunakan Ward and Peppard Pada PT. Grahacipta Bangko Jaya, e-Proceeding of Engineering, 3(1) : 1004

(Muhammad Afrianto, Eko Darwiyanto, \& Gede Agung Ary Wisudiawan, 2016, Perencanaan Strategis Sistem Informasi Menggunakan Ward and Peppard Pada PT. Grahacipta Bangko Jaya, eProceeding of Engineering, 3(1) : 1004

Putra, P, S, Kemas Rahmat SW, \& Erda Guslinar Perdana, 2014, Perencanaan Strategis Sistem Informasi Menggunakan Metode Ward and Peppard Pada PT. Medika Antapani, e-Proceeding of Engineering, 1(1) : 794

Lexy J. Moleong, M.A, 2013, Metodologi Penelitian Kualitatif, Bandung: PT Remaja Rosdakarya (https://rosda.co.id/pendidikan-keguruan/486metodologi-penelitian-kualitatif-edisi 